\title{
Flora da Reserva Ducke, Estado do Amazonas, Brasil: Hypericaceae
}

\author{
Milena Ventrichi Martins ${ }^{1},{ }^{\circ}$ Gustavo Hiroaki Shimizu $^{1,3}$ e Volker Bittrich ${ }^{2}$
}

Recebido: 14.02.2018; aceito: 15.05.2018

\begin{abstract}
Flora of the Reserva Ducke, Amazonas State, Brazil: Hypericaceae). The species of Hypericaceae recorded for the Reserva Ducke, Amazonas State, are presented, including identification key, descriptions, illustrations, comments about geographic distribution and habitats. The family is represented in the area by five species of the genus Vismia: Vismia cauliflora, V. cayennensis, V. guianensis, V. japurensis, and V. sandwithii.
\end{abstract}

Keywords: Amazon, Clusioid clade, lacre, Vismia

RESUMO - (Flora da Reserva Ducke, Estado do Amazonas, Brasil: Hypericaceae). São apresentadas as espécies de Hypericaceae registradas para a Reserva Ducke, Estado do Amazonas, incluindo chave de identificação, descrições, ilustrações, comentários sobre distribuição geográfica e hábitats. A família está representada na área por cinco espécies do gênero Vismia: Vismia cauliflora, V. cayennensis, V. guianensis, V. japurensis e V. sandwithii.

Palavras-chave: Amazônia, clado Clusioide, lacre, Vismia

\section{Introdução}

Hypericaceae foi por longo tempo incluída em Clusiaceae, mas atualmente é reconhecida como uma família independente, com base em estudos filogenéticos (Wurdack \& Davis 2009, Ruhfel et al. 2011, APG IV 2016). Faz parte do clado Clusioide, que também inclui Bonnetiaceae, Calophyllaceae, Clusiaceae e Podostemaceae, sendo grupo-irmão desta última (Wurdack \& Davis 2009, Ruhfel et al. 2011). A família Hypericaceae possui distribuição cosmopolita, compreendendo sete gêneros e aproximadamente 480 espécies (Stevens 2001 em diante).

No Brasil ocorrem dois gêneros: Hypericum L., com 23 espécies e maior diversidade no sul do país, e Vismia Vand., com 30 espécies e maior diversidade na região amazônica (Martins et al. 2018, Flora do Brasil 2020). O gênero Vismia foi estabelecido por Domingos Vandelli (1788), que o segregou de Hypericum por apresentar características como pétalas e nectários pilosos.

As espécies de Vismia são conhecidas popularmente no Brasil como "lacre", que se refere ao seu exsudato normalmente amarelado ou alaranjado. São caracterizadas pelo indumento nos ramos, folhas e/ou estruturas florais, estames reunidos em fascículos e presença de pontoações e/ou estrias glandulares (vittae) em estruturas vegetativas e/ou reprodutivas (Stevens 2007).

Entre os produtos do "Projeto Flora da Reserva Ducke" (histórico em Hopkins 2005), relativos a uma importante Reserva Florestal no município de Manaus, Amazonas, foi gerado um guia de campo ricamente ilustrado e focado na identificação de famílias e espécies, baseado principalmente em caracteres vegetativos (Ribeiro et al.1999). Além disso, foram publicados tratamentos taxonômicos para 20 famílias de samambaias e licófitas e 36 de angiospermas, por exemplo: Pirani (2005), Prado (2005), Pennington (2006), Prance \& Silva (2006), Maas et al. (2007) e Taylor et al. (2007). O presente trabalho soma-se a essa série de monografias, adicionando o tratamento de Hypericaceae. No levantamento original presente no guia (Ribeiro \& Bittrich 1999), foram listadas cinco espécies de Vismia (sob Clusiaceae).

1. Universidade Estadual de Campinas, Instituto de Biologia, Departamento de Biologia Vegetal, Rua Monteiro Lobato, 255, 13083-970 Campinas, SP, Brasil

2. Universidade Estadual de Campinas, Rua Dr. Mario de Nucci, 500, 13083-290 Campinas, SP, Brasil

3. Autor para correspondência: gustavoshimizu@gmail.com 


\section{Material e métodos}

A área de estudo foi a Reserva Florestal Adolpho Ducke, gerenciada pelo Instituto Nacional de Pesquisas da Amazônia (INPA), e que perfaz $100 \mathrm{~km}^{2}$, sendo composta principalmente por floresta de terra firme (Hopkins 2005). Foi realizada uma viagem de coleta em dezembro de 2016, percorrendo áreas de terra firme, não sazonalmente inundadas pela cheia dos rios, e vegetações secundárias. Essa expedição objetivou também a obtenção de registros fotográficos e de amostras de folhas para futuros trabalhos de filogenia. As exsicatas foram depositadas no herbário da Universidade Estadual de Campinas (UEC). Também foram analisadas coleções de Hypericaceae da Reserva Ducke dos herbários CEN, CEPEC, ESA, INPA, MBM, NY, RB, SP, UB, UEC e US (acrônimos segundo Thiers, continuamente atualizado), pessoalmente ou via speciesLink (http:// inct.splink.org.br/) e Herbário Virtual Reflora (http:// www.herbariovirtualreflora.jbrj.gov.br/).

Para as identificações das espécies foram consultadas bibliografias especializadas (Reichardt 1878, Ewan 1962) e obras com descrições originais, além de análise comparativa de exsicatas e fotos de coleções-tipo. Os dados de floração e frutificação foram obtidos por meio das etiquetas das exsicatas e observações de campo. As descrições de família e gênero abrangem todas as espécies neotropicais e foram baseadas em Ewan (1962), Robson (1998) e Stevens (2007).

\section{Resultados e Discussão}

No Estado do Amazonas, Hypericaceae está representada por 18 espécies de Vismia, das quais cinco ocorrem na Reserva Ducke: Vismia cauliflora A.C.Sm., V. cayennensis (Jacq.) Pers., V. guianensis (Aubl.) Choisy, V.japurensis Reichardt e V. sandwithii Ewan. Esse levantamento difere do tratamento anterior (Ribeiro \& Bittrich 1999) pela adição de $V$. japurensis e pela identificação do exemplar de Vismia cf. gracilis Hieron. como V. guianensis. Todas as espécies levantadas pertencem a Vismia seção Vismia, cujos representantes apresentam muitos estames por fascículo e muitos óvulos por lóculo (Reichardt 1878).

Hypericaceae Juss., Gen. pl. 254. 1789.

Árvores, arbustos, subarbustos ou ervas. Folhas opostas, ocasionalmente alternas ou verticiladas, simples, sem estípulas, pecioladas ou sésseis, margens inteiras, glabras ou indumentadas. Inflorescências cimosas, paniculadas ou então unifloras, terminais, raramente axilares ou caulifloras, brácteas e bractéolas presentes, normalmente caducas. Flores bissexuadas, actinomorfas, diclamídeas, pediceladas ou subsésseis; sépalas 4-5, persistentes, glabras ou indumentadas; pétalas 4-5, glabras ou indumentadas; estames geralmente numerosos, livres ou dispostos em fascículos ou em anel ao redor do ovário, anteras rimosas; estaminódios nectaríferos presentes ou ausentes; ovário súpero, 2-5-carpelar, uni ou 5-locular, estiletes 2-5, livres, estigmas capitados. Frutos bagas ou cápsulas septicidas, sementes diminutas.

Vismia Vand., Fl. lusit. bras. spec. 51. 1788.

Árvores ou arbustos; ramos frequentemente indumentados, com tricomas estrelados ou dendríticos; exsudato alaranjado, vermelhoalaranjado ou amarelado. Folhas pecioladas ou subsésseis, concolores ou discolores, lâminas foliares com pontoações nigrescentes, normalmente evidentes, muitas vezes com tricomas ferrugíneos na face abaxial; venação broquidódroma ou mista. Inflorescências geralmente multifloras. Flores homostilas ou heterostilas; sépalas 5, de prefloração quincuncial, unidas na base, cartáceas, subcoriáceas ou coriáceas, margens hialinas ou membranáceas, podendo apresentar estrias (vittae) e/ou pontoações nigrescentes ou avermelhadas; pétalas 5, brancas, esverdeadas ou amareladas, de prefloração cocleada a contorta, livres, podendo apresentar estrias (vittae) e/ou pontoações nigrescentes ou avermelhadas, face adaxial parcial ou inteiramente lanosa; estames dispostos em cinco fascículos, cada um com três a muitos estames, opostos às pétalas, muitas vezes vilosos, persistentes ou não nos frutos, filetes inseridos em diferentes alturas, glândulas nigrescentes presentes ou ausentes no ápice das anteras; estaminódios nectaríferos 5, alternos às pétalas, com indumento, geralmente persistentes nos frutos; ovário 5-carpelar, 5-locular, (2-) $\infty$ óvulos por lóculo, podendo apresentar pontoações nigrescentes, estiletes 5 , filiformes, persistentes no fruto, às vezes com indumento. Bagas globosas, ovais ou oblongas, coriáceas, sépalas adpressas, patentes, ascendentes ou reflexas no fruto maduro; sementes reniformes, geralmente numerosas, marrons, foveoladas. 
Chave de identificação das espécies de Vismia ocorrentes na Reserva Ducke

1. Folhas 35-75 cm de comprimento, oblanceoladas, longo-elípticas a fusiformes; inflorescências caulifloras, subsésseis, congestas 1. Vismia cauliflora

1. Folhas menores que $35 \mathrm{~cm}$ de comprimento, ou quando iguais ou maiores, elípticas a oblongas; inflorescências terminais, pedunculadas, laxas

2. Folhas glabras na face abaxial; sépalas reflexas no fruto maduro

2. Vismia cayennensis

2. Folhas pilosas, pubescentes ou tomentosas na face abaxial; sépalas adpressas, ascendentes ou patentes no fruto maduro

3. Folhas com pontoações nigrescentes não evidentes na face abaxial, encobertas pelo indumento; flores homostilas; pétalas com face adaxial lanosa apenas em uma das metades longitudinais 4. Vismia japurensis

3. Folhas com pontoações nigrescentes evidentes a fortemente evidentes na face abaxial, às vezes encobertas pelo indumento; flores heterostilas; pétalas com face adaxial inteiramente lanosa 4. Estrias e/ou pontoações nigrescentes ausentes ou pouco evidentes nas pétalas; fascículos de estames não persistentes no fruto; bagas ovais 3. Vismia guianensis

4. Estrias e/ou pontoações nigrescentes evidentes nas pétalas; fascículos de estames persistentes no fruto; bagas globosas 5. Vismia sandwithii

1. Vismia cauliflora A.C.Sm., J. Arnold Arbor. 20: 299. 1939.

Figuras 1a-d, 2a-d

Árvores, 4-13 m alt.; ramos cilíndricos, velutinos, tricomas marrom-escuros, estrelados; exsudato alaranjado. Lâminas 35-75 × 11-17 cm, subcoriáceas, discolores, oblanceoladas, longoelípticas a fusiformes, ápice acuminado, base atenuada, arredondada a subcordada, face adaxial glabrescente, com tricomas estrelados e ferrugíneos nas nervuras, opaca, face abaxial pilosa, com tricomas estrelados ferrugíneos, pontoações nigrescentes evidentes, nervuras secundárias 12-24 pares, fortemente proeminentes na face abaxial; pecíolos 6-8 mm compr. Inflorescências caulifloras, subsésseis, congestas; brácteas 2-6 mm compr., lineares. Flores provavelmente homostilas; pedicelos 1,5-2 $\mathrm{mm}$ compr.; sépalas 5-6 × 2-2,5 mm, cartáceas, castanhas, oblongo-obovais a oblongo-oblanceoladas, ápice agudo, margens membranáceas em 3 sépalas, com pontoações nigrescentes, face adaxial com estrias nigrescentes in sicco (cor não observada in vivo), face abaxial com tricomas estrelados, ferrugíneos, persistentes; pétalas 7-9 × 2-3,2 mm, amarelas a verdeclaras, oblongas, ápice arredondado, base atenuada, face adaxial inteiramente lanosa, face abaxial com estrias e pontoações nigrescentes in sicco (cor não observada in vivo), na metade superior; fascículos de 7-8 estames, 3-3,5 mm compr., lanosos na porção mediana, persistentes, ápice da antera com glândula nigrescente; nectários 1-3 mm compr., retangulares, persistentes; ovário 2-3 mm compr., globoso, com pontoações nigrescentes, estiletes 2-7 mm compr., com pontoações nigrescentes, glabros, geralmente persistentes. Bagas 0,7-1,2 cm compr., acinzentadas, globosas; sépalas \pm patentes a ascendentes no fruto maduro.

Material examinado: BRASIL. AmAzonas: Manaus, Reserva Ducke, 20-VI-1958, fl., L. Coelho 21 (INPA); ibid., 2-VII-1963, fl., W.A. Rodrigues 5322 (INPA); ibid., 9-VI-1976, fl., A.R. Oliveira s.n. (INPA59906); ibid., 23-IX-1994, fr., J.E.L.S. Ribeiro 1433 (INPA); ibid., 1-XI-1994, fr., A. Vicentini et al. 766 (INPA, NY, RB, SP, UEC); ibid., 19-IX-1997, fl., fr., M.D.A. de Souza 421 (INPA, NY, UEC); ibid., 13-XII-2016, bot., fl., fr., M.V. Martins et al. 388 (UEC).

Vismia cauliflora ocorre apenas no Brasil, no Estado do Amazonas (Flora do Brasil 2020), sendo encontrada na Reserva Ducke no sub-bosque de florestas de vertente. A espécie pode ser reconhecida pelas folhas compridas, de até $75 \mathrm{~cm}$ compr., com o ápice acuminado, e pelas inflorescências caulifloras, subsésseis e congestas. Registrada com botões florais em dezembro, flores em junho, julho, setembro e dezembro e frutos em setembro, novembro e dezembro.

2. Vismia cayennensis (Jacq.) Pers., Syn. pl. 2: 86. 1806.

Figuras 1e-h, 2e-i, 4a

Árvores, 4-8 m alt.; ramos cilíndricos, glabrescentes; exsudato vermelho-alaranjado. Lâminas $6-11,5 \times 3,8-4,5 \mathrm{~cm}$, subcoriáceas, concolores, ovais a 


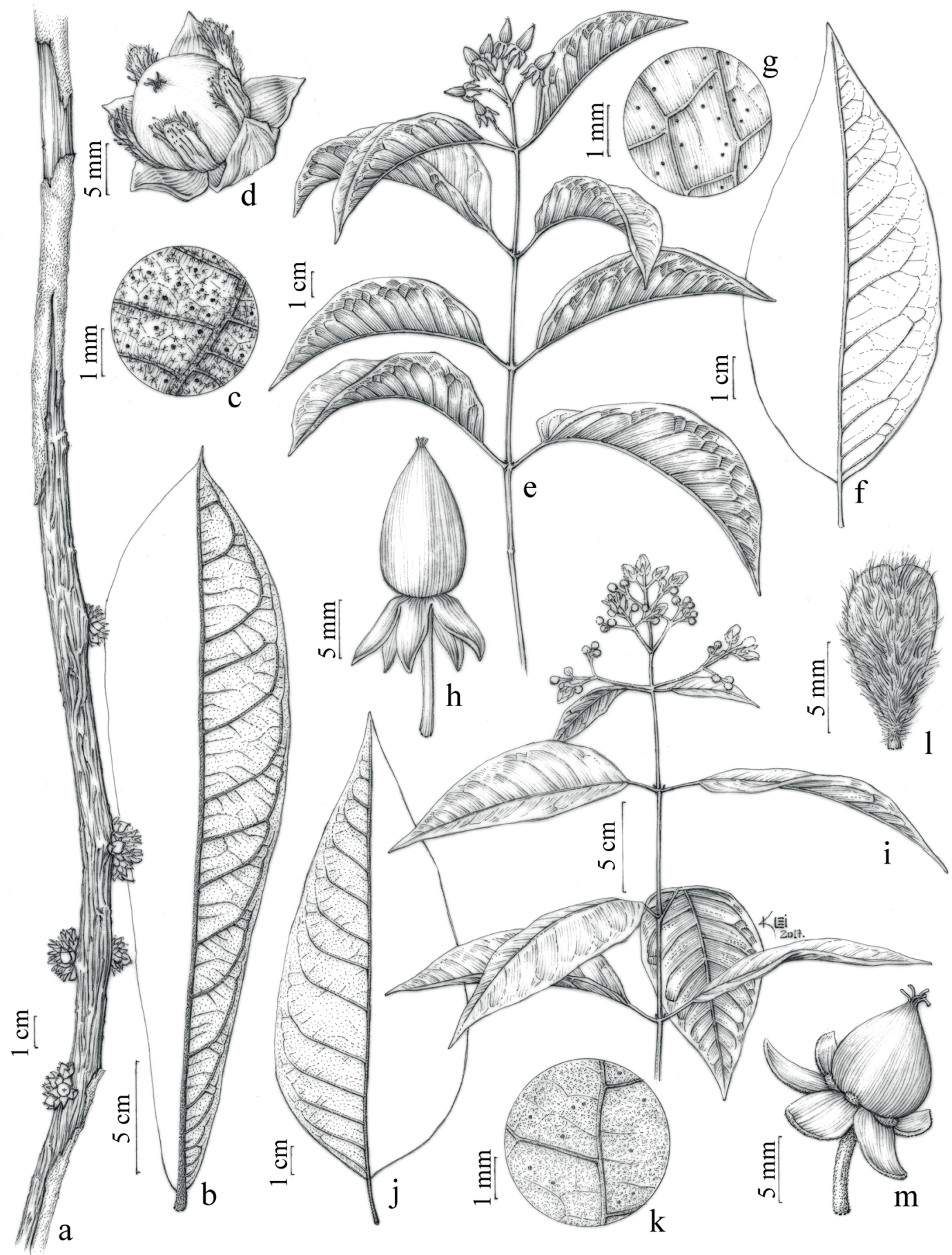

Figura 1. a-d. Vismia cauliflora. a. Ramo com inflorescências caulifloras. b. Face abaxial da folha. c. Detalhe das pontoações nigrescentes evidentes na face abaxial foliar. d. Fruto. e-h. Vismia cayennensis. e. Ramo com frutos. f. Face abaxial da folha. g. Detalhe das pontoações nigrescentes evidentes na face abaxial foliar. h. Fruto. i-m. Vismia guianensis. i. Ramo com botões florais. j. Face abaxial da folha. k. Detalhe das pontoações nigrescentes evidentes na face abaxial foliar. 1. Pétala com face adaxial inteiramente lanosa. $\mathrm{m}$. Fruto.

Figure 1. a-d. Vismia cauliflora. a. Branch with cauliflorous inflorescences and caducous indument. b. Leaf abaxial surface. c. Detail of the black dots evident on the leaf abaxial surface. d. Fruit. e-h. Vismia cayennensis. e. Branch with fruits. f. Leaf abaxial surface. g. Detail of the black dots evident on the leaf abaxial surface. h. Fruit. i-m. Vismia guianensis. i. Branch with flower buds. j. Leaf abaxial surface. k. Detail of the black dots evident on the leaf abaxial surface. 1. Petal with adaxial surface entirely lanose. m. Fruit. 

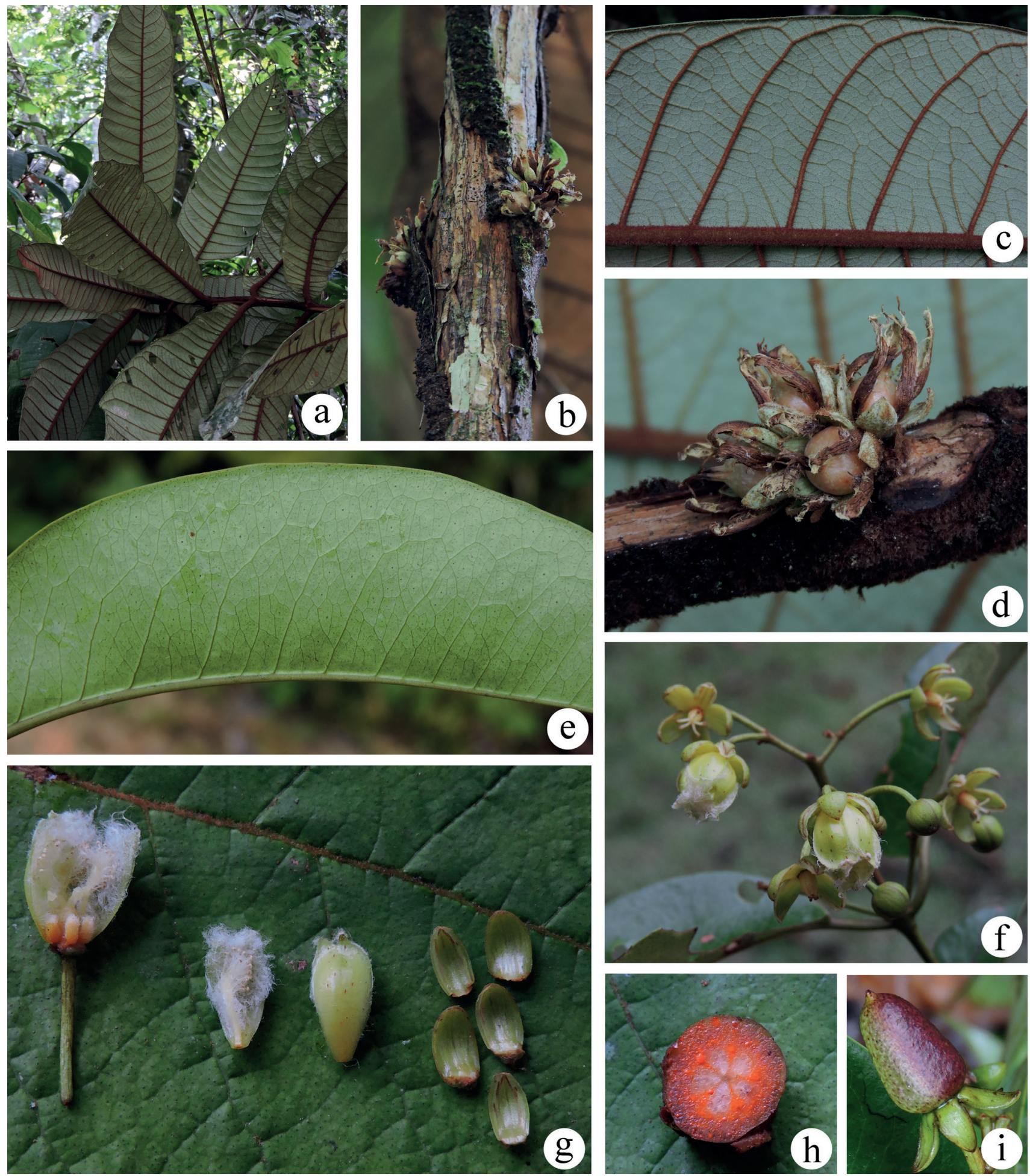

Figura 2. a-d. Vismia cauliflora. a. Ramo com folhas. b. Ramo com inflorescências caulifloras. c. Detalhe da face abaxial foliar. d. Ramo com frutos jovens. e-i. Vismia cayennensis. e. Detalhe da face abaxial foliar. f. Inflorescência. g. Flor dissecada, com pétalas e sépalas removidas. h. Fruto jovem em corte transversal, evidenciando o exsudato. i. Fruto. Fotos: G.H. Shimizu.

Figure 2. a-d. Vismia cauliflora. a. Branch with leaves. b. Branch with cauliflorous inflorescences. c. Detail of the leaf abaxial surface. d. Branch with young fruits. e-i. Vismia cayennensis. e. Detail of the leaf abaxial surface. f. Inflorescence. g. Dissected flower with petals and sepals removed. h. Young fruit in cross section evidencing the exsudate. i. Fruit. Photos: G.H. Shimizu. 
elíptico-oblongas, ápice acuminado, base arredondada a cuneada, face adaxial glabra, nítida, face abaxial glabra, pontoações nigrescentes evidentes; nervuras secundárias 10-15 pares, pouco proeminentes na face abaxial; pecíolos 8-10 mm compr. Inflorescências terminais, pedunculadas, laxas; brácteas diminutas, precocemente caducas. Flores heterostilas; pedicelos 7-15 mm compr.; sépalas 5-6,2 × 1,5-2,5 mm, subcoriáceas, verdes, oblongo-elípticas, ápice agudo, margens membranáceas em 3 sépalas, com 1-2 pontoações nigrescentes no ápice, face adaxial com poucas estrias ou pontoações nigrescentes in vivo e in sicco, face abaxial com tricomas diminutos estrelados, alvos, persistentes; pétalas 8-10 × 3,9-4,1 mm, amarelas a verde-claras, obovais a oblanceoladas, ápice arredondado, base atenuada, face adaxial inteiramente lanosa, face abaxial com poucas pontoações avermelhadas in vivo e nigrescentes in sicco, na metade superior; fascículos de 40-50 estames, ca. $8 \mathrm{~mm}$ compr., lanosos, não persistentes, ápice da antera com glândula nigrescente; nectários 1-1,3 mm compr., retangulares a oblanceolados, não persistentes; ovário ca. $2 \mathrm{~mm}$ compr., oval-oblongo, com poucas pontoações nigrescentes, estiletes 1,5-3 mm compr., sem pontoações nigrescentes, glabros, geralmente persistentes. Bagas 1-1,5 cm compr., avermelhadas a marrons, ovais, oval-oblongas a elíptico-oblongas; sépalas reflexas no fruto maduro.

Material examinado: BRASIL. AmAzonAs: Manaus, Reserva Ducke, 1-IX-1966, fl., G.T. Prance et al. 2164 (INPA, NY); ibid., 30-XII-1976, fl., J.R. Nascimento 215 (INPA); ibid., 12-VII-1994, fl., M.J.G. Hopkins et al.1465 (INPA, UEC); ibid., 19-VII-1994, fr., J.E.L.S. Ribeiro et al. 1341 (INPA, NY, SP, UEC); ibid., 24-X-1994, fr., C.A. Sothers \& P. Stumpe 236 (INPA, RB, UEC); ibid., 22-VIII-1996, fr., J.E.L.S. Ribeiro 1836 (INPA, NY, RB, UEC); ibid., 12-XII-2016, fl., fr., M.V. Martins et al. 382 (UEC).

Vismia cayennensis é amplamente distribuída nos países da região amazônica, ocorrendo também em Trinidad e Tobago (Ewan 1962). No Brasil está presente nas regiões Centro-Oeste, Nordeste e Norte (Flora do Brasil 2020), em clareiras e capoeiras, sendo muito comum também em áreas degradadas, em solo argiloso e arenoso. A espécie pode ser reconhecida pelas folhas glabras e nítidas na face adaxial, estames e nectários caducos e sépalas reflexas no fruto maduro. Os materiais da coleta G.T. Prance et al. 2164 estavam identificados como $V$. tenuinervia (M.E.Berg) N.Robson, todavia os consideramos como V. cayennensis pelo número menor de nervuras secundárias (10 a 15 pares em $V$. cayennensis vs. 20 a 28 em $V$. tenuinervia). Registrada com flores em julho, setembro e dezembro e com frutos em julho, agosto, outubro e dezembro.

3. Vismia guianensis (Aubl.) Choisy, Prodr. monogr. Hypéric. 34. 1821.

Figuras 1i-m, 4b-f

Árvores ou arbustos, 2-5 m alt.; ramos cilíndricos, pubescentes, tricomas esbranquiçados a ferrugíneos, estrelados; exsudato amarelado. Lâminas 5-14 × 2-6 cm, cartáceas, discolores, ovais a elípticas ou lanceoladas, ápice acuminado, base cuneada ou atenuada, face adaxial esparsamente pubérula a glabra, às vezes nítida, face abaxial tomentosa, com tricomas estrelados ferrugíneos, pontoações nigrescentes evidentes, às vezes encobertas pelo indumento; nervuras secundárias 8-10 pares, proeminentes na face abaxial; pecíolos 7-15 mm compr. Inflorescências terminais, pedunculadas, laxas; brácteas 2-5 mm compr., lineares, às vezes precocemente caducas. Flores heterostilas; pedicelos 6-8 mm compr.; sépalas 4-5 × 1,5-2 mm, subcoriáceas, castanhas, oval-deltoides a lanceoladas, ápice agudo, margens membranáceas em 3 sépalas, com estrias nigrescentes, face adaxial com estrias avermelhadas in vivo e nigrescentes in sicco, evidentes, face abaxial com tricomas estrelados ferrugíneos, persistentes; pétalas 5-8 $\times 2-3 \mathrm{~mm}$, verde-claras, obovais, obovaloblongas a oblanceoladas, ápice arredondado, base atenuada, face adaxial inteiramente lanosa, face abaxial com estrias e pontoações avermelhadas in vivo e nigrescentes in sicco geralmente ausentes (raramente 1-2 pontoações presentes); fascículos de ca. 30 estames, 2,5-8 $\mathrm{mm}$ compr., glabrescentes a vilosos na porção mediana e vilosos na parte livre dos filetes, não persistentes, ápice da antera sem glândula nigrescente; nectários 0,8-1,2 mm compr., retangulares, persistentes; ovário 2-3 mm compr., oval, geralmente sem pontoações nigrescentes, estiletes 3-3,5 mm compr., sem pontoações nigrescentes, geralmente vilosos, geralmente persistentes. Bagas 0,8-1 cm compr., marrons, ovais; sépalas patentes a adpressas no fruto maduro.

Material examinado: BRASIL. AmAzonAs: Manaus, Reserva Ducke, 28-IV-1988, fl., J.F. Ramos 1889 (INPA, UEC); ibid., 10-V-1988, fl., D. Coelho \& R.P. Lima D-31 (INPA, UEC); ibid., 14-VI-1988, fl., J.L. Santos \& R.P. Lima 921 (INPA, NY, SP, UEC); ibid., 
17-IX-1988, fr., J.F. Pruski et al. 3268 (INPA, NY, RB, SP, UEC); ibid., 4-VII-1993, fl., fr., J.E.L.S. Ribeiro et al. 1015 (INPA, RB, UEC); ibid., 7-VIII-1995, fr., M. Nee 46198 (INPA, UEC); ibid., 10-VII-2004, fl., V.C. Souza \& D.A.C. Pinho 29989 (ESA, INPA); ibid., 13-XII-2016, bot., fl., fr., M.V. Martins et al. 389 (UEC).

Vismia guianensis apresenta distribuição ampla, ocorrendo no Brasil, Guiana, Guiana Francesa, Suriname, Trinidad e Tobago e Venezuela (Robson 1998). No Brasil é comumente encontrada em borda de vegetação secundária e áreas degradadas em solo arenoso a argiloso, nas regiões Centro-Oeste, Nordeste, Norte e Sudeste (Flora do Brasil 2020). É uma espécie bastante variável morfologicamente e pode ser reconhecida pelas pétalas geralmente sem pontoações e pelo ápice da antera sem glândula nigrescente. Registrada com botões florais em dezembro, flores em abril, maio, junho, julho e dezembro e frutos em julho, agosto, setembro e dezembro.

4. Vismia japurensis Reichardt in Mart., Eichler \& Urb., F1. bras. 12(1): 209, t. 39. 1878.

Figuras 3a-e, 4g-1, 5a

Árvores ou arbustos, 4-10 m alt.; ramos cilíndricos, pubescentes, tricomas ferrugíneos, estrelados; exsudato alaranjado. Lâminas 17-20 × 4,5-10 cm, subcoriáceas, discolores, oval-lanceoladas ou elíptico-lanceoladas, ápice agudo ou acuminado, base arredondada, face adaxial glabra, às vezes nítida, face abaxial pubescente, com tricomas estrelados ferrugíneos, pontoações nigrescentes não evidentes, encobertas pelo indumento; nervuras secundárias 8-15 pares, proeminentes na face abaxial; pecíolos 15-20 mm compr. Inflorescências terminais, pedunculadas, laxas; brácteas não observadas. Flores homostilas; pedicelos 4-5 mm compr.; sépalas 6-8 $\times 4-5 \mathrm{~mm}$, coriáceas, marrom-esverdeadas, oval-deltoides, ápice agudo, margens membranáceas, com estrias nigrescentes, face adaxial com estrias avermelhadas in vivo e nigrescentes in sicco, evidentes, face abaxial com tricomas estrelados, ferrugíneos, persistentes; pétalas 7-8 × 4-6 mm, verde-amareladas, obovais, ápice truncado, base atenuada, face adaxial lanosa apenas em uma das metades longitudinais, com estrias nigrescentes evidentes, face abaxial com estrias e pontoações avermelhadas in vivo e nigrescentes in sicco, na metade superior; fascículos de 20-30 estames, 6-8 mm compr., lanosos, persistentes, ápice da antera com glândula nigrescente; nectários ca. 1,5 mm compr., oblongos, persistentes; ovário ca. $2 \mathrm{~mm}$ compr., oval-oblongo, com pontoações nigrescentes, estiletes ca. $4 \mathrm{~mm}$ compr., com pontoações nigrescentes, glabrescentes, persistentes. Bagas 1-1,3 cm compr., verdes, globosas; sépalas ascendentes no fruto maduro.

Material examinado: BRASIL. Amazonas: Manaus, Reserva Ducke, 31-IX-1994, bot., fl., P.A.C.L. Assunção et al. 766 (INPA, MBM, NY, UB, UEC); ibid., 12-XII-2016, fl., fr., M.V. Martins et al. 380A (UEC), ibid., 12-XII-2016, fl., fr., M.V. Martins et al. 385 (UEC).

Material adicional examinado: BRASIL. AmAzonAs: Manaus-Porto Velho Highway, km 255, 18-III-1974, fr., G.T. Prance et al. 20691 (INPA, NY, UEC, US); Presidente Figueiredo, 16-XII-2016, fl., fr., M.V. Martins et al. 390 (UEC); ibid., 16-XII-2016, fl., fr., M.V. Martins et al. 391 (UEC); ibid., 16-XII-2016, fl., fr., M.V. Martins et al. 392 (UEC). Roraima: Caracaraí, 16-IX-2010, fl., fr., F.N. Cabral et al. 281 (INPA, NY, UEC).

Vismia japurensis ocorre no Brasil, Colômbia, Equador, Guiana, Suriname e Venezuela (Robson 1998). No Brasil está presente nas regiões CentroOeste e Norte (Flora do Brasil 2020), sendo encontrada próximo de curso d'água e em borda de vegetação secundária. Pode ser caracterizada pelas sépalas grandes (6-8 $\times$ 4-5 mm), fortemente coriáceas até mesmo no fruto, e pela face adaxial das pétalas lanosa apenas em uma das metades longitudinais. Registrada com botões e flores em setembro e dezembro e frutos em dezembro.

5. Vismia sandwithii Ewan, Contr. U.S. Natl. Herb. 35(5): 309. 1962.

Figuras 3f-j, 5b-g

Árvores, 5-16 m alt.; ramos cilíndricos, tomentosos, tricomas ferrugíneos, estrelados; exsudato alaranjado a vermelho-alaranjado. Lâminas 13-30 (-40) × 7,5-12 cm, cartáceas, discolores, elípticas a oblongas, ápice acuminado, base arredondada a subcordada, face adaxial glabrescente, com tricomas estrelados, ferrugíneos, opaca, face abaxial tomentosa, com tricomas estrelados pedunculados, ferrugíneos, pontoações nigrescentes fortemente evidentes; nervuras secundárias 9-14 pares, proeminentes na face abaxial; pecíolos 12-15 mm compr. Inflorescências terminais, pedunculadas, laxas; brácteas 1-2 mm compr., trigonais a oblongas. Flores heterostilas; pedicelos 3-5 mm compr.; sépalas 6-9 × 3-7 mm, subcoriáceas, esverdeadas, ovais a oval-oblongas, 


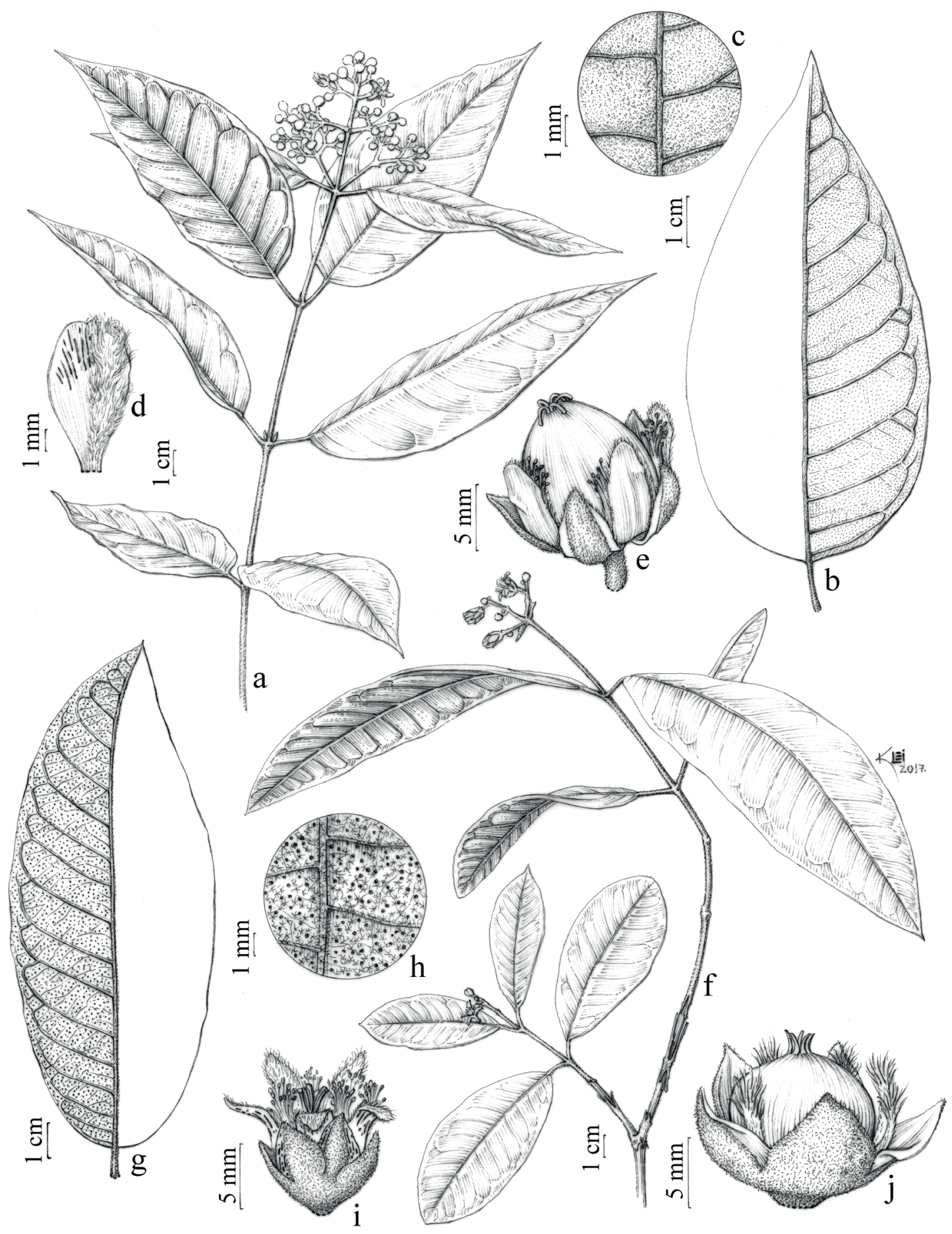

Figura 3. a-e. Vismia japurensis. a. Ramo com inflorescência. b. Face abaxial da folha. c. Detalhe da face abaxial foliar. d. Pétala com face adaxial lanosa apenas em uma das metades longitudinais. e. Fruto. f-j. Vismia sandwithii. f. Ramo com inflorescência. g. Face abaxial da folha. h. Detalhe das pontoações nigrescentes fortemente evidentes na face abaxial foliar. i. Flor. j. Fruto.

Figure 3. a-e. Vismia japurensis. a. Branch with inflorescence. b. Leaf abaxial surface. c. Detail of the leaf abaxial surface. d. Petal with adaxial surface lanose only on one of the longitudinal halves. e. Fruit. f-j. Vismia sandwithii. f. Branch with inflorescence. g. Leaf abaxial surface. h. Detail of the black dots strongly evident on the leaf abaxial surface. i. Flower. j. Fruit. 

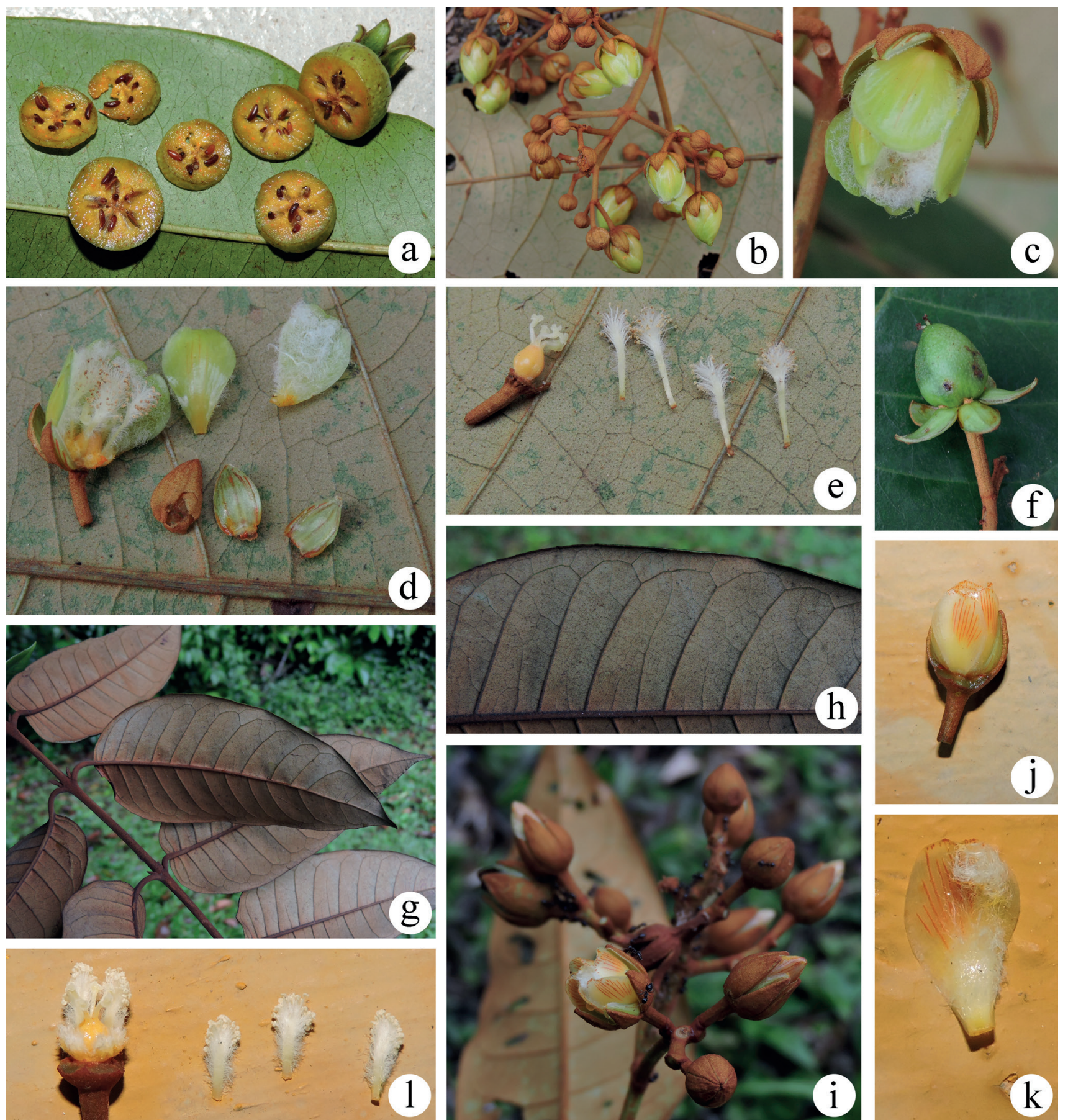

Figura 4. Vismia cayennensis. a. Fruto cortado transversalmente, evidenciando as sementes. b-f. Vismia guianensis. b. Parte da inflorescência. c. Flor. d. Flor dissecada, com pétalas e sépalas removidas. e. Flor dissecada, com gineceu à esquerda e fascículos de estames à direita. f. Fruto. g-1. Vismia japurensis. g. Ramo com folhas. h. Detalhe da face abaxial foliar. i. Inflorescência. j. Flor com duas sépalas removidas. k. Pétala com face adaxial lanosa apenas em uma das metades longitudinais. 1. Flor dissecada, com cálice e corola removidos e com três fascículos de estames destacados à direita. Fotos: G.H. Shimizu.

Figure 4. Vismia cayennensis. a. Fruit cut crosswise evidencing the seeds. b-f. Vismia guianensis. b. Part of the inflorescence. c. Flower. d. Dissected flower with petals and sepals removed. e. Dissected flower with gynoecium to the left and stamen fascicles to the right. f. Fruit. g-l. Vismia japurensis. g. Branch with leaves. h. Detail of the leaf abaxial surface. i. Inflorescence. j. Flower with two sepals removed. k. Petal with adaxial surface lanose only on one of the longitudinal halves. 1. Dissected flower with calyx and corolla removed and with three stamen fascicles detached to the right. Photos: G.H. Shimizu. 

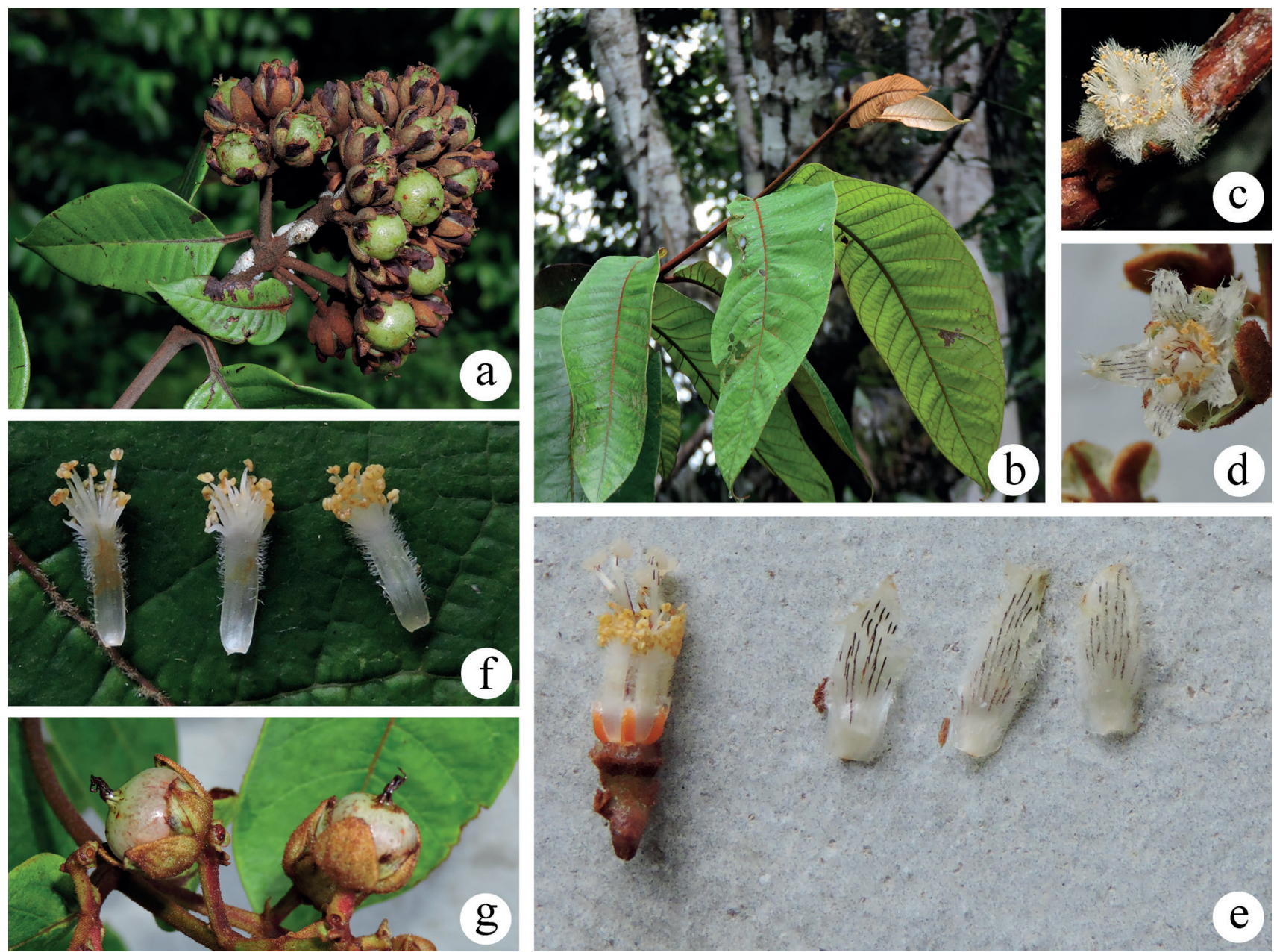

Figura 5. Vismia japurensis. a. Ramo com frutos. b-g. Vismia sandwithii. b. Ramo com folhas. c. Flor brevistila. d. Flor longistila. e. Flor dissecada, com sépalas e pétalas removidas e três pétalas à direita. f. Fascículos de estames. g. Frutos. Fotos: G.H. Shimizu.

Figure 5. Vismia japurensis. a. Branch with fruits. b-g. Vismia sandwithii. b. Branch with leaves. c. Brevistylous flower. d. Longistylous flower. e. Dissected flower with sepals and petals removed and three petals to the right. f. Stamen fascicles. g. Fruits. Photos: G.H. Shimizu.

ápice subagudo, margens membranáceas em 3 sépalas, com estrias e pontoações nigrescentes, face adaxial com estrias e pontoações nigrescentes in vivo e in sicco, evidentes, face abaxial com tricomas estrelados ferrugíneos, persistentes; pétalas $8 \times 1,5-2,5 \mathrm{~mm}$, verde-claras a brancas, oblongas, ápice cuneado, base atenuada, face adaxial inteiramente lanosa, com estrias e pontoações nigrescentes evidentes; face abaxial com estrias e pontoações nigrescentes in vivo e in sicco, menos na base; fascículos de ca. 20 estames, $7-9 \mathrm{~mm}$ compr., hirsutos na porção mediana, persistentes, ápice da antera com glândula nigrescente; nectários ca. 1,5 mm compr., linear-oblongos, persistentes; ovário ca. $2 \mathrm{~mm}$ compr., oval-oblongo, com estrias nigrescentes, estiletes 2-3 mm compr., com estrias nigrescentes, glabrescentes, persistentes. Bagas ca. 0,8 cm compr., verde-acinzentadas a verde-arroxeadas, globosas; sépalas ascendentes no fruto maduro.
Material examinado: BRASIL. AmazonAs: Manaus, Reserva Ducke, 15-IV-1966, fr., W. Rodrigues \& D. Coelho 7685 (INPA); ibid., XI-1972, fl., M.F. Silva \& W. Rodrigues 1050 (INPA); ibid., 10-I-1981, fl., fr., S. Renner 95 (INPA, US); ibid., 9-III-1994, fr., J.E.L.S. Ribeiro et al. 1219 (INPA, NY, UEC); ibid., 17-XI-1994, bot., fl., J.E.L.S. Ribeiro et al. 1495 (INPA, NY, RB, UEC); ibid., 25-XI-1994, fl., P.A.C.L. Assunção 95 (INPA, UEC); ibid., 16-XII-1994, fl., fr., J.E.L.S. Ribeiro \& C.F. da Silva 1539 (INPA, UEC); ibid., 9-I-2002, fr., M. Alves \& S. Heald 2352 (CEN, CEPEC, INPA, NY, SP); ibid., 17-IV-2015, fr., L.C. Marinho \& D.L. Santos 1003 (INPA); ibid., 12-XII-2016, fl., M.V. Martins et al. 380 (UEC); ibid., 12-XII-2016, fl., M.V. Martins et al. 381 (UEC); ibid., 12-XII-2016, fl., M.V. Martins et al. 387 (UEC).

Vismia sandwithii ocorre no Brasil, Colômbia, Equador, Guiana, Guiana Francesa, Suriname e 
Venezuela (Robson 1998). No Brasil é registrada na região Norte (Flora do Brasil 2020), sendo encontrada na Reserva Ducke em capoeiras e floresta de terra firme. A espécie pode ser reconhecida pelas pontoações nigrescentes fortemente evidentes na face abaxial das folhas e pode ser confundida com $V$. macrophylla Kunth, que não ocorre na Reserva Ducke. Diferem principalmente pelo número de nervuras secundárias nas folhas, que são de 9 a 14 pares em $V$. sandwithii e 10 a 22 pares em $V$. macrophylla, pela ausência de papilas diminutas brancas na face abaxial das folhas em $V$. sandwithii (presentes em V. macrophylla) e pelas estrias no ovário e nos estiletes presentes em $V$. sandwithii (vs. pontoações nigrescentes em V. macrophylla). Registrada com botões em novembro, flores em janeiro, novembro e dezembro e frutos em janeiro, março, abril e dezembro.

\section{Agradecimentos}

À CAPES/PROTAX pelas bolsas de Pós-Doutorado concedidas a MVM e GHS. À FAPESP pelo auxílio concedido (2016/50382-5). Ao Michael Hopkins, curador do herbário INPA, pela hospitalidade e ajuda constante, em vários aspectos. Ao Klei Sousa pelas ilustrações. À Ana Claudia Alencar pela companhia no trabalho de campo. À Fernanda Cabral pelo auxílio com a autorização de coleta e com o herbário. À Maria do Carmo E. Amaral pelo incentivo e auxílio constantes.

\section{Literatura citada}

APG IV. 2016. An update of the Angiosperm Phylogeny Group classification for the orders and families of flowering plants: APG IV. Botanical Journal of the Linnean Society 181: 1-20.

Ewan, J. 1962. Synopsis of the South American species of Vismia (Guttiferae). Contributions from the United States National Herbarium 35: 293-377.

Flora do Brasil 2020 (em construção). 2018. Hypericaceae. Jardim Botânico do Rio de Janeiro. Disponível em http:// www.floradobrasil.jbrj.gov.br/reflora/floradobrasil/ FB133 (acesso em 06-II-2018).

Hopkins, M.J.G. 2005. Flora da Reserva Ducke, Amazonas, Brasil. Rodriguésia 56: 9-25.

Maas, P.J.M., Maas, H. \& Miralha, J.M.S. 2007. Flora da Reserva Ducke, Amazonas, Brasil: Annonaceae. Rodriguésia 58: 617-662.

Martins, M.V., Shimizu, G.H., Bittrich, V. \& Amaral, M.C.E. 2018. Vismia conduplicata (Hypericaceae), a new species from Mato Grosso, Brazil. Phytotaxa 338: $125-129$.

Pennington, T.D. 2006. Flora da Reserva Ducke, Amazonas, Brasil: Sapotaceae. Rodriguésia 57: 251-366.

Pirani, J.R. 2005. Flora da Reserva Ducke, Amazonas, Brasil: Rutaceae. Rodriguésia 56: 189-204.
Prado, J. 2005. Flora da Reserva Ducke, Amazonas, Brasil: Pteridophyta - Polypodiaceae. Rodriguésia 56: 76-84.

Prance, G.T. \& Silva, M.F. 2006. Flora da Reserva Ducke, Amazonas, Brasil: Caryocaraceae. Rodriguésia 57: 155-157.

Reichardt, H.G. 1878. Hypericaceae. In: C.F.P. Martius, A.W. Eichler \& I. Urban (eds.). Flora Brasiliensis. Frid. Fleischer, Leipzig, v. 12, pars 1, pp. 182-212, t. 33-39.

Ribeiro, J.E.L.S. \& Bittrich, V. 1999. Clusiaceae. In: J.E.L.S. Ribeiro, M.J.G. Hopkins, A. Vicentini, C.A. Sothers, M.A.S. Costa, J.M. Brito, M.A.D. Souza, L.H.P. Martins, L.G. Lohmann, P.A.C.L. Assunção, E.C. Pereira, C.F. Silva, M.R. Mesquita \& L.C. Procópio. Flora da Reserva Ducke. Guia de identificação das plantas vasculares de uma floresta de terra-firme na Amazônia Central. INPA-DFID, Manaus, pp. 244-257.

Ribeiro, J.E.L.S., Hopkins, M.J.G., Vicentini, A., Sothers, C.A., Costa, M.A.S., Brito, J.M., Souza, M.A.D., Martins, L.H.P., Lohmann, L.G., Assunção, P.A.C.L., Pereira, E.C., Silva, C.F., Mesquita, M.R. \& Procópio, L.C. 1999. Flora da Reserva Ducke. Guia de identificação das plantas vasculares de uma floresta de terra-firme na Amazônia Central. INPA-DFID, Manaus.

Robson, N.K.B. 1998. Vismia. In: J.A. Steyermark, P.E. Berry \& B.K. Holst (eds.). Flora of the Venezuelan Guayana. Missouri Botanical Garden Press, Saint Louis, v. 4, pp. 322-329.

Ruhfel, B.R., Bittrich, V., Bove, C.P., Gustafsson, M.H.G., Philbrick, C.T., Rutishauser, R., Xi, Z. \& Davis, C.C. 2011. Phylogeny of the Clusioid clade (Malpighiales): evidence from the plastid and mitochondrial genomes. American Journal of Botany 98: 306-325.

Stevens, P.F. 2001 onwards. Angiosperm Phylogeny Website. Disponível em http://www.mobot.org/ MOBOT/research/APweb/ (acesso em 06-II-2018).

Stevens, P.F. 2007. Hypericaceae. In: K. Kubitzki (ed.). The families and genera of vascular plants. Flowering plants. Eudicots: Berberidopsidales, Buxales, Crossosomatales, Fabales p.p., Geraniales, Gunnerales, Myrtales p.p., Proteales, Saxifragales, Vitales, Zygophyllales, Clusiaceae alliance, Passifloraceae alliance, Dilleniaceae, Huaceae, Picramniaceae, Sabiaceae. Springer, Berlin, v. 9, pp. 194-201.

Taylor, C.M., Campos, M.T.V.A. \& Zappi, D. 2007. Flora da Reserva Ducke, Amazonas, Brasil: Rubiaceae. Rodriguésia 58: 549-616.

Thiers, B. [continuously updated]. Index Herbariorum: a global directory of public herbaria and associated staff. New York Botanical Garden's Virtual Herbarium. Disponível em http://sweetgum.nybg.org/science/ih/ (acesso em 06-II-2018).

Vandelli, D. 1788. Florae Lusitanicae et Brasiliensis specimen. Typographia Academico-Regia, Coimbra.

Wurdack, K.J. \& Davis, C.C. 2009. Malpighiales phylogenetics: gaining ground on one of the most recalcitrant clades in the angiosperm tree of life. American Journal of Botany 96: 1551-1570. 